\title{
Analysis of fuel consumption of China light duty vehicle test cycle for passenger car(CLTC-P)
}

\author{
Meng Zhou*, Chongzhi Zhong, and Jingyuan Li \\ China Automotive Technology and Research Center, China
}

\begin{abstract}
Keywords: fuel consumption, NEDC cycle, CLTC-P cycle, cold start emission, air conditioning fuel consumption.
\end{abstract}

\begin{abstract}
Through the fuel consumption test of several listed vehicles in China, the basic fuel consumption results of cold start under CLTC-P cycle, the fuel consumption results of vehicles under the condition of air conditioning on, and the fuel consumption results of vehicles under the condition of air conditioning off are measured. At the same time, the differences between NEDC cycle and CLTC-P cycle in China's fuel consumption certification test are compared, and the results of fuel consumption test are combined The fuel consumption test results under CLTC-P cycle are higher than those under NEDC cycle, and the fuel consumption test procedures under Chinese condition are more in line with the actual driving situation in China.
\end{abstract}

\begin{tabular}{|c|c|}
\hline \multicolumn{2}{|c|}{ Abbreviations } \\
\hline NEDC & New European driving cycle \\
\hline CLTC-P & China light duty vehicle test cycle for passenger car \\
\hline $\mathrm{CO}$ & Carbon monoxide \\
\hline $\mathrm{HC}$ & hydrocarbons \\
\hline $\mathrm{CO}_{2}$ & carbon dioxide \\
\hline
\end{tabular}

\section{Introduction}

In recent years, China's automobile industry has developed vigorously, with a significant increase in car ownership. In the whole year of 2019, China's production and sales of passenger vehicles have reached $21.36 \mathrm{~m}$ cars and 21.444 million cars, and the sales volume of cars has reached 10.144 million. With the gradual popularization of cars, people's requirements for cars are no longer limited to driving functions, and important factors such as fuel economy and driving safety are gradually coming into the vision of the public. At the same time, under the pressure of energy-saving and emission reduction policies, such as the rise of new energy vehicles, double points (average fuel consumption points + new energy vehicle points), automobile manufacturers are increasingly strict in fuel consumption control[1]. At present, China's fuel consumption certification results are based on GB / T

\footnotetext{
*Corresponding author: zhoumeng@catarc.ac.cn
} 
19233-2008 The NEDC cycle of Measurement methods of fuel consumption for light-duty vehicles is tested at the ECE and the EUDC drive cycles to represent both urban and suburban driving scenarios[2]. Due to the fixed acceleration, deceleration and gentle speed, the test result is lower than the actual driving fuel consumption in China[3]. The question whether NEDC cycle can represent the actual working condition in China is raised constantly. A new cycle for the type approval test for actual road driving conditions in China with more realworld driving features is of great necessity[4].Under this background, the fuel consumption test in China comes into being. In conclusion, in order to study the fuel economy of vehicles in China, the test of China's condition and fuel consumption is analyzed. This article presents fuel consumption of the passenger car research results obtained in the conditions of a chassis dynamometer[5-6]. A Comparison of Fuel Consumption for Vehicles Tested over the NEDC cycle, CLTC-P cycle[7].

\section{Test conditions and test methods}

\subsection{Introduction of test cycles}

\subsubsection{NEDC test cycle}

As Figure 1 shows for NEDC working condition curve of GB / T 19233-2008 Measurement methods of fuel consumption for light-duty vehicles. The operation cycle consists of one part (urban operation cycle) and two parts (suburban operation cycle). During the test of Part 1 (urban operation cycle), the average speed is $19 \mathrm{~km} / \mathrm{h}$, the effective driving time is $195 \mathrm{~s}$, the theoretical driving distance of each cycle is $1.013 \mathrm{~km}$, and the equivalent distance of four cycles is $4.052 \mathrm{~km}$. During the two (suburban operation cycle) tests, the average speed is $62.6 \mathrm{~km} / \mathrm{h}$, the effective driving time is $400 \mathrm{~s}$, the theoretical driving distance of each cycle is $6.955 \mathrm{~km}$, the maximum speed is $120 \mathrm{~km} / \mathrm{h}$, the maximum acceleration is $0.833 \mathrm{~m} / \mathrm{s}^{2}$, and the maximum deceleration is $-1.389 \mathrm{~m} / \mathrm{s}^{2}$. Under the overall test condition, the average speed is $33.6 \mathrm{~km} / \mathrm{h}$, the acceleration ratio is $23.2 \%$, the deceleration ratio is $16.6 \%$, the constant speed ratio is $37.5 \%$, and the idle speed ratio is $24.8 \%$

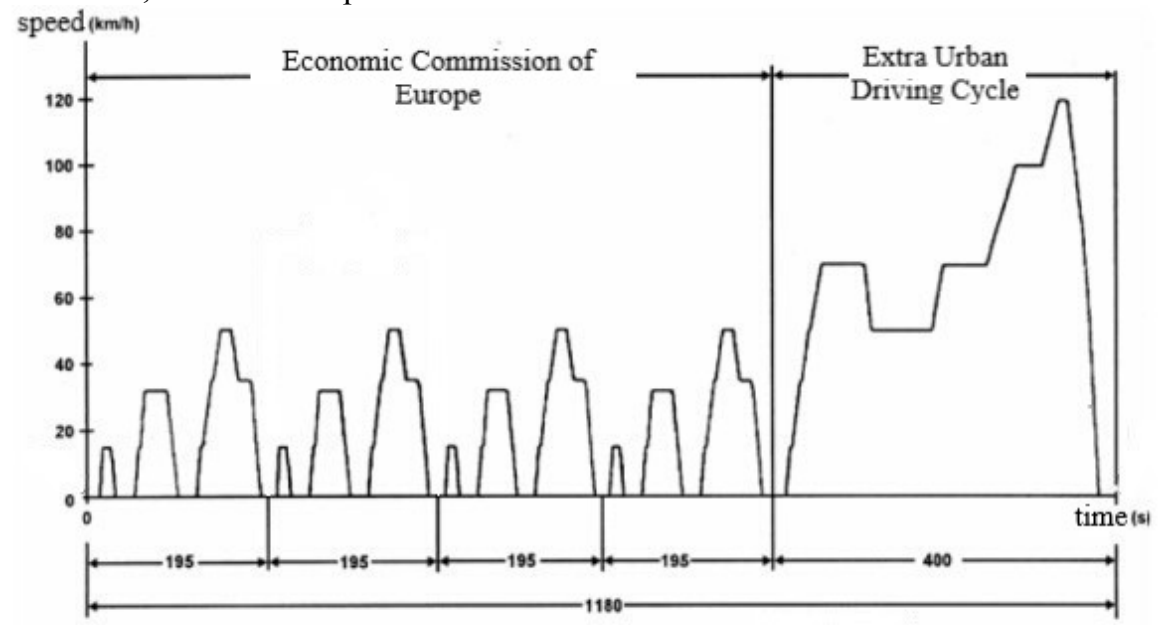

Fig 1. Speed time curve of NEDC cycle condition. 


\subsubsection{CLTC-P test cycle}

China light duty vehicle test cycle for passenger car (CLTC-P) include three speed ranges of 674 seconds (one part) at low speed, 693 seconds (two parts) at medium speed and 433 seconds (three parts) at high speed. The working conditions are 1800 seconds in total. CLTC$\mathrm{P}$ cycle accounts the weight of each cycle in overall traffic, introduces significant biases, particularly when plotting emission vs. average speed curves[8], with a total mileage of $14.48 \mathrm{~km}$ and a maximum speed of $114 \mathrm{~km} / \mathrm{h}$, The maximum acceleration is $1.470 \mathrm{~m} / \mathrm{s}^{2}$, the maximum deceleration is $-1.470 \mathrm{~m} / \mathrm{s}^{2}$, the average speed is $28.96 \mathrm{~km} / \mathrm{h}$, the acceleration ratio is $28.78 \%$, the deceleration ratio is $26.44 \%$, the constant speed ratio is 22.67 , and the idle speed ratio is $22.11 \%$

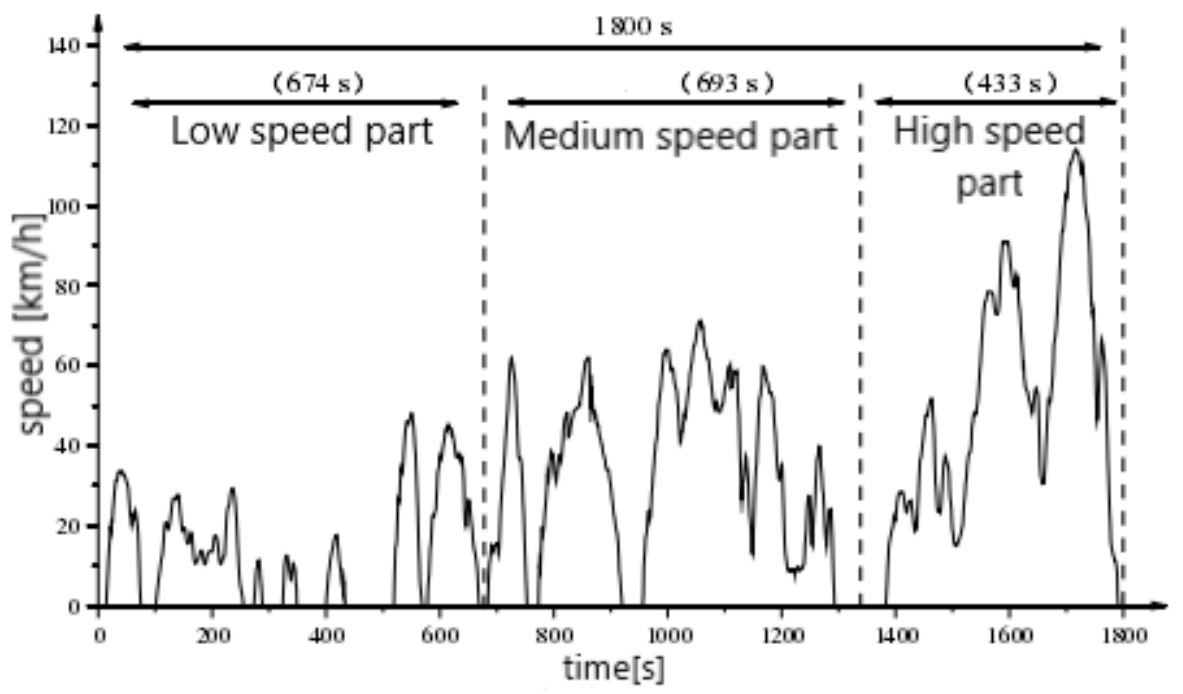

Fig. 2. Speed time curve of CLTC-P cycle condition.

\subsubsection{Comparison between CLTC-P cycle and NEDC cycle}

The total duration of CLTC-P cycle is 1800 seconds, which is significantly longer than 1180 seconds of NEDC cycle. A longer working time is very helpful to reflect the actual emission level of the vehicle. One part of NEDC (urban operation cycle) consists of four single urban operation cycles, but CLTC-P cycle includes 674 seconds of low speed and 693 seconds of medium speed. The total duration of the two parts is 1367 seconds, accounting for $75.9 \%$ of the total duration, which is higher than $66.1 \%$ of NEDC cycle. CLTC-P cycle is more in line with the traffic characteristics of more congestion and long idle time in urban areas of China. The decisive factor of vehicle fuel consumption level often depends on the high-speed section. Although the maximum vehicle speed of cltc-p cycle is $114 \mathrm{~km} / \mathrm{h}$ slightly lower than $120 \mathrm{~km}$ / h of NEDC, the maximum acceleration of $1.06 \mathrm{~m} / \mathrm{s}^{2}$ is significantly higher than $0.833 \mathrm{~m} / \mathrm{s}^{2}$ of NEDC cycle, and the radical CLTC-P cycle has a greater test on the test vehicle. Throughout the whole situation, CLTC-P cycle greatly reduces the proportion of uniform speed conditions, improves the proportion of acceleration and deceleration, and uses different acceleration and deceleration instead of the fixed acceleration and deceleration of NEDC conditions, which is in line with the actual situation of long time of low speed and frequent congestion of road traffic in China.

\subsection{Test method}


The fuel consumption test in CLTC-P is divided into two parts: basic fuel consumption and air conditioning fuel consumption outside the cycle.

\subsubsection{Basic fuel consumption test}

The cold-start condition is an important factor affecting vehicle emissions from gasoline direct injection (GDI) and port fuel injection (PFI) vehicles[9].The basic fuel consumption refers to the emission test of exhaust pollutants after cold start at room temperature in accordance with CLTC-P under the environment of $23{ }^{\circ} \mathrm{C} \pm 5{ }^{\circ} \mathrm{C}$, absolute humidity of air and engine intake $(\mathrm{H})$ (water / dry air) $(\mathrm{g} / \mathrm{kg}$ ) of $5.5<(\mathrm{H})$ (water / dry air) $<12.2$, in accordance with GB 18352.6-2016 the load and inertia of the dynamometer shall be set according to the provisions of appendix $\mathrm{CC}$, in which the driving resistance of the vehicle shall be determined by sliding method, and the test fuel consumption result is the basic fuel consumption result[10].

\subsubsection{Air conditioning fuel consumption outside the cycle test}

The fuel consumption of the air conditioner outside the cycle is divided into two parts: 1 . Fuel consumption measurement of the vehicle with the air conditioner on; 2. Fuel consumption measurement of the vehicle with the air conditioner off[11].

2.2.2.1 environment condition

1) the ambient temperature shall be $30 \pm 2{ }^{\circ} \mathrm{C}$.

2) the relative humidity of the environment shall be $50 \% \pm 5 \%$.

3) the solar radiation intensity is $850 \pm 45 \mathrm{~W} / \mathrm{m} 2$ during the fuel consumption test under the condition of vehicle immersion and air conditioning on, and there is no solar radiation in other test processes. The solar radiation intensity is set based on the plane position of the highest point of the roof.

\subsubsection{Air conditioning setting}

1) For the automatic control air conditioner, it is set to the "automatic" mode, the temperature is set to no more than $25^{\circ} \mathrm{C}$, the air circulation switch is set to the internal circulation (except that the internal / external circulation cannot be switched under the "automatic" mode) and the blowing surface mode position (except that the blowing surface mode cannot be switched under the "automatic" mode)[12].

2) For manual controlled air conditioning, set the temperature condition switch to the maximum cooling mode position; set the air volume regulating switch to the middle position (round to the high position); set the air circulation switch to the internal circulation position and the face blowing mode.

3)For vehicles with middle and rear exhaust outlets, close the middle and rear exhaust outlets and control switches (if any). The front air outlet opening is set to the maximum.

Test procedure

2.2.2.3 Test procedure

1)Test preparation $5 \%$.

a) the ambient temperature shall be $30 \pm 2{ }^{\circ} \mathrm{C}$, and the relative humidity shall be $50 \% \pm$

b)place the vehicle and connect the exhaust sampling system and other test equipment to confirm that there is no leakage in the fuel pipeline and exhaust fully.

c)set the load and inertia of the dynamometer according to appendix cc of GB 18352.62016, in which the driving resistance of the vehicle is determined by sliding method

2) Vehicle fuel consumption measurement $\left(\mathrm{FC}_{\mathrm{on}}\right)$ with air conditioning on 
a) Open all windows, turn the air circulation switch of the car air conditioner to the external circulation position, and turn the air volume regulating switch to the middle position (round to the high position).

b) the vehicle is driven at a constant speed of $90 \pm 2 \mathrm{~km} / \mathrm{h}$ for $20 \mathrm{~min}$.

c) close the engine and all windows. After setting the solar radiation intensity, the vehicle shall stand for at least $30 \mathrm{~min}$.

d) turn on and set the vehicle air conditioning as required.

e) the vehicle is tested according to CLTC-P, and the fuel consumption results are obtained

f) during the test, the real-time continuous record shall be made at the acquisition frequency of no less than $1 \mathrm{~Hz}$, and the temperature change of the measuring point is required. When the test is carried out for 15 minutes, the average temperature of the test point (except for the test point affected by the driver's breathing) shall not be greater than $23{ }^{\circ} \mathrm{C}$, otherwise, the test shall be stopped, and the test shall be carried out in sequence after reset according to 2.2.2.2. When the test is carried out for 15 minutes to the end of the test (except for the idle period), the accumulated time when the average temperature of all temperature measuring points (except for the measuring points affected by the driver's breathing) exceeds $23{ }^{\circ} \mathrm{C}$ shall not exceed $20 \mathrm{~s}$, otherwise the test will be invalid, and the test will be carried out in sequence after the air conditioning is reset.

3) Vehicle fuel consumption measurement $\left(\mathrm{FC}_{\text {off }}\right)$ with air conditioning off

a)turn off the solar radiation and vehicle air conditioning, open all windows, set the air circulation switch of vehicle air conditioning to the external circulation position, and set the air volume regulating switch to the middle position (round to the high position). The vehicle is driven at a constant speed of $90 \pm 2 \mathrm{~km} / \mathrm{h}$ for $20 \mathrm{~min}$.

b) after the air conditioner and all windows of the vehicle are closed, the test shall be carried out in accordance with the test procedure in Chapter 6 of GB / T 19233-2008 under the driving condition of Chinese vehicles (CLTC-P).

\subsection{Calculate fuel consumption}

1) With the calculated $\mathrm{HC}, \mathrm{CO}$ and $\mathrm{CO}_{2}$ emissions, the low speed part, the medium speed part, the high speed part and the comprehensive fuel consumption are calculated respectively.

2) Calculate the fuel consumption in litres per $100 \mathrm{~km}(\mathrm{~L} / 100 \mathrm{~km})$ using the following formula:

$$
\mathrm{FC}=\frac{0.1155}{\mathrm{D}}\left[(0.866 \times \mathrm{HC})+(0.429 \times \mathrm{CO})+\left(0.273 \times \mathrm{CO}_{2}\right)\right]
$$

3) Calculate the fuel consumption of the off cycle air conditioner of the vehicle type according to the following formula

$$
\mathrm{FC}_{\mathrm{AC}}=\left(\mathrm{FC}_{\mathrm{ON}}-\mathrm{FC}_{\mathrm{OFF}}\right)
$$

In the formula: $\mathrm{FC}_{\mathrm{AC}}$ - fuel consumption of automobile air conditioning, unit: $\mathrm{L} / 100 \mathrm{~km}$; $\mathrm{FC}_{\mathrm{ON}}$ - fuel consumption of vehicle with air conditioning on, unit: $\mathrm{L} / 100 \mathrm{~km} ; \mathrm{FC}_{\mathrm{OFF}}$ - fuel consumption of vehicle with air conditioning off, unit: L / 100km.

4) Calculation of fuel consumption in China

Fuel consumption under CLTC-P cycle= basic fuel consumption + fuel consumption of air conditioner outside the circulation $\times 0.25$

\subsection{Introduction to test vehicle}

We have selected 10 models that are more common on the market, and the model parameters are shown in Table 1. Based on the current car sales situation, we have selected 6 sedans and 4 multi-purpose passenger vehicles, mainly including in cylinder direct injection and 
turbocharged models, with the displacement ranging from $1.2 \mathrm{~L}$ to $2.5 \mathrm{~L}$, basically covering the selection range of civil models.

Table 1. Test vehicle parameters.

\begin{tabular}{|c|c|c|c|c|c|}
\hline NO. & Type & $\begin{array}{c}\text { Output } \\
\text { volume }\end{array}$ & $\begin{array}{c}\text { Oil } \\
\text { supply }\end{array}$ & $\begin{array}{c}\text { Intake } \\
\text { mode }\end{array}$ & $\begin{array}{c}\text { Trans } \\
\text { mission }\end{array}$ \\
\hline A & Sedan & 1.5 & GDI & Turbo & AT \\
\hline B & SUV & 1.5 & GDI & Turbo & CVT \\
\hline C & Sedan & 1.8 & GDI & Turbo & DCT \\
\hline D & SUV & 2 & GDI & Turbo & AT \\
\hline E & Sedan & 1.8 & GDI & Turbo & AT \\
\hline F & SUV & 2 & GDI & Turbo & AT \\
\hline G & Sedan & 1.2 & GDI & Turbo & CVT \\
\hline H & SUV & 2 & MPI & $\begin{array}{c}\text { Natural } \\
\text { inspiration }\end{array}$ & AT \\
\hline I & Sedan & 2.5 & GDI & $\begin{array}{c}\text { Natural } \\
\text { inspiration }\end{array}$ & AT \\
\hline J & Sedan & 2 & GDI & Turbo & AT \\
\hline
\end{tabular}

\section{Test results and analysis}

\subsection{Test results}

The fuel consumption of 10 models under CLTC-P cycle in China is tested, and the basic fuel consumption under cold start at room temperature is named $\mathrm{FC}_{\mathrm{BASE}}$, The fuel consumption result of the vehicle with air conditioning on is named $\mathrm{FC}_{\mathrm{ON}}$, The fuel consumption result of the vehicle with the air conditioning off is named $\mathrm{FC}_{\mathrm{OFF}}[13]$, Thus, the fuel consumption of the off cycle air conditioner of the vehicle is named $\mathrm{FC}_{\mathrm{AC}}$, The final calculated fuel consumption in China is named $\mathrm{FC}_{\text {CLTC-P, }}$ At the same time, the fuel consumption $\mathrm{FC}_{\mathrm{NEDC}}$, of the model under NEDC cycle and the fuel limit $\mathrm{FC}_{\text {LIMIT }}$ of the corresponding model in accordance with GB 19578-2014 fuel consumption limit for passenger cars are listed, Data of test results are shown in Table 2.

Table 2. Fuel consumption results of 10 models of CLTC-P and NEDC.

\begin{tabular}{|c|c|c|c|c|c|c|c|}
\hline $\mathrm{NO}$. & $\mathrm{FC}_{\text {BASE }}$ & $\mathrm{FC}_{\mathrm{ON}}$ & $\mathrm{FC}_{\mathrm{OFF}}$ & $\mathrm{FC}_{\text {AC }}$ & $\mathrm{FC}_{\text {CLTC-P }}$ & $\mathrm{FC}_{\text {NEDC }}$ & $\mathrm{FC}_{\text {LIMIT }}$ \\
\hline $\mathrm{A}$ & 8.57 & 9.77 & 6.99 & 2.79 & 9.26 & 5.90 & 7.20 \\
\hline $\mathrm{B}$ & 6.90 & 9.06 & 7.01 & 2.05 & 7.41 & 6.40 & 8.40 \\
\hline $\mathrm{C}$ & 8.30 & 10.08 & 7.48 & 2.60 & 8.95 & 6.40 & 8.00 \\
\hline $\mathrm{D}$ & 10.87 & 11.88 & 10.03 & 1.84 & 11.33 & 9.10 & 9.20 \\
\hline $\mathrm{E}$ & 9.87 & 10.84 & 8.88 & 1.96 & 10.36 & 7.80 & 8.80 \\
\hline $\mathrm{F}$ & 8.77 & 11.11 & 8.20 & 2.92 & 9.50 & 6.50 & 8.40 \\
\hline $\mathrm{G}$ & 6.62 & 9.18 & 6.39 & 2.79 & 7.31 & 5.60 & 7.20 \\
\hline $\mathrm{H}$ & 8.94 & 10.47 & 8.11 & 2.36 & 9.53 & 8.30 & 8.80 \\
\hline $\mathrm{I}$ & 7.75 & 9.39 & 7.31 & 2.08 & 8.27 & 6.00 & 8.40 \\
\hline $\mathrm{J}$ & 7.26 & 9.86 & 6.96 & 2.91 & 7.98 & 6.20 & 8.40 \\
\hline
\end{tabular}

\subsection{Test results analysis}


As shown in Figure 3, in the cold start pollutant emission test, the basic fuel consumption results of 10 models in CLTC-P are higher than NEDC fuel consumption results, with an average growth of $23.55 \%$, among which the average growth of multipurpose passenger vehicle fuel consumption is $17.44 \%$, the average growth of car fuel consumption is $27.04 \%$, the average growth of fuel consumption of models with displacement above $2.0 \mathrm{~L}$ and $2.0 \mathrm{~L}$ is $21.64 \%$, and the average growth of fuel consumption of vehicles with displacement above $2.0 \mathrm{~L}$ is $2.64 \%$ The average fuel consumption of vehicles below $2.0 \mathrm{~L}$ increased by $25.46 \%$. It can be found that in the cold start fuel consumption results of CLTC-P, the growth rate of multi-purpose passenger vehicles is small, the results are better than that of cars, and the fuel consumption results of large displacement vehicles above $2.0 \mathrm{~L}$ are better than that of small displacement vehicles[14].

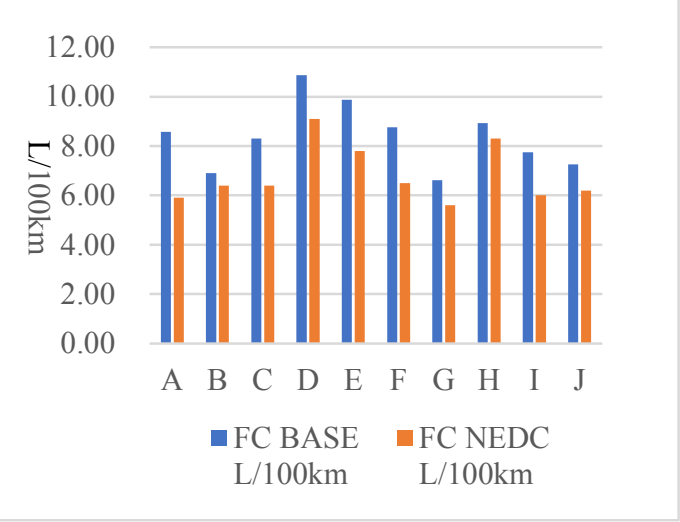

Fig. 3. Fuel consumption results of CLTC-P cycle and NEDC cycle cold start.

In order to facilitate the analysis of the fuel consumption level under two driving cycles, the fuel consumption factors $\mathrm{K}_{\mathrm{BASE}}$ and $\mathrm{K}_{\mathrm{NEDC}}$ are introduced. The ratio of the fuel consumption test results under driving conditions to the corresponding fuel consumption limits in GB19578-2014 fuel consumption limits for passenger cars is as follows:

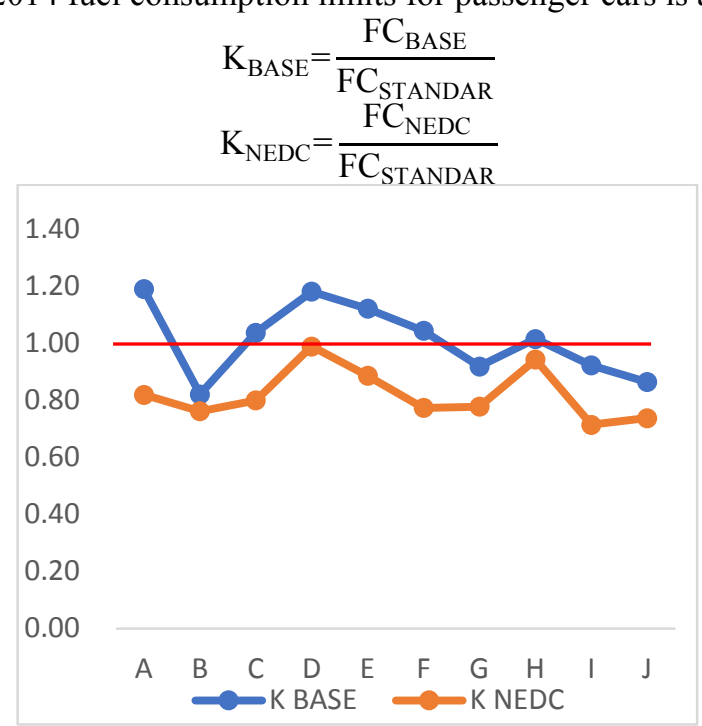

Fig. 4. Fuel consumption factor distribution of cold start test under CLTC-P and NEDC cycles. 
As shown in Figure 4, under NEDC condition, the fuel consumption factors are all less than 1.0, meeting the fuel consumption limit requirements. The average level is kept at 0.82 . Under cltc-p cycle, the fuel consumption factors of four models are less than 1.0. The remaining models exceed the fuel consumption limit requirements, the average level is kept at 1.01, and the maximum value is 1.19 , The average level of fuel consumption factor of SUV model is 1.02, and the average level of fuel consumption factor of sedan model is 1.01. Under CLTC-P cycle, the fuel consumption of the two models is equivalent. The average level of fuel consumption factor of the models with displacement above $2.0 \mathrm{~L}$ and $2.0 \mathrm{~L}$ is 1.01 , and the average level of fuel consumption factor of the models with displacement below $2.0 \mathrm{~L}$ is 1.02. In conclusion, under CLTC-P cycle, the fuel consumption of the cold start is increased The fuel consumption results are distributed near the fuel consumption limit.

\subsubsection{Analysis of fuel consumption of air conditioner outside the cycle}

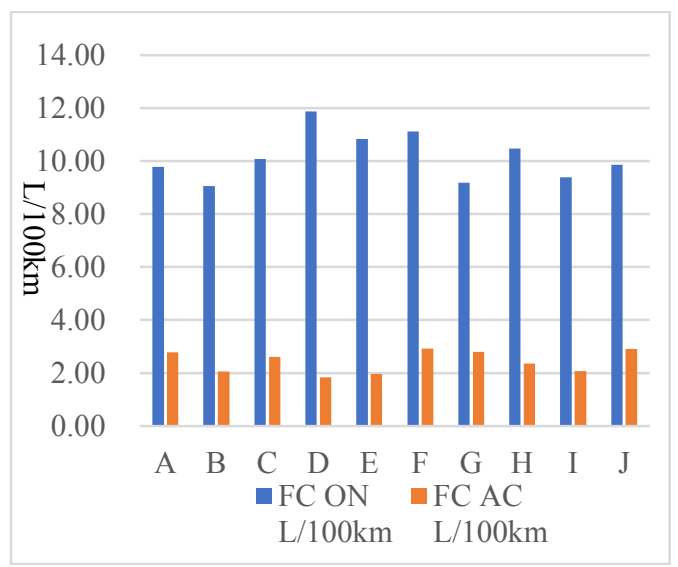

Fig. 5. Results of vehicle fuel consumption and air conditioning fuel consumption outside the cycle under the condition of air conditioning on.

As shown in Figure 5, the fuel consumption of out of cycle air conditioning: $\mathrm{FC}_{\mathrm{AC}}=\left(\mathrm{FC}_{\mathrm{on}}\right.$ - $\mathrm{FC}_{\mathrm{off}}$ ), in which the fuel consumption of out of cycle air conditioning is basically maintained between $1.5 \mathrm{~L} / 100 \mathrm{~km}-3 \mathrm{~L} / 100 \mathrm{~km}$, the maximum value is $2.92 \mathrm{~L} / 100 \mathrm{~km}$, and the average value is $2.43 \mathrm{~L} / 100 \mathrm{~km}$, The average fuel consumption of multi-purpose passenger cars and cars is $2.29 \mathrm{~L} / 100 \mathrm{~km}$ and $2.52 \mathrm{~L} / 100 \mathrm{~km}$ respectively. In terms of fuel consumption under the condition of air conditioning on, the proportion of multi-purpose passenger vehicles and cars reaches $21.73 \%$ and $25.50 \%$; the proportion of vehicles with displacement of $2.0 \mathrm{~L}$ and above reaches $23.17 \%$, and the proportion of vehicles with displacement of $2.0 \mathrm{~L}$ and below reaches $25.09 \%$. In contrast, the fuel consumption of the large displacement vehicle is relatively small due to the high engine power, while the power of the small displacement vehicle is relatively small. When the air conditioner is turned on, the load increases, resulting in the fuel consumption growth slightly higher than that of the large displacement vehicle.

\subsubsection{Analysis of fuel consumption in CLTC-P}

The calculation method of cltc-p fuel consumption is $\mathrm{FC}_{\mathrm{CLTC}-\mathrm{P}}=\mathrm{FC}_{\mathrm{BASE}}+\mathrm{FC}_{\mathrm{AC}} \times 0.25$. In order to facilitate the analysis and introduction of fuel consumption factors $\mathrm{K}_{\text {CLTC-P }}$ and $\mathrm{K}_{\mathrm{NEDC}}$, the ratio of fuel consumption results of driving condition test and fuel consumption limits for passenger cars in GB19578-2014. The formula is as follows: 


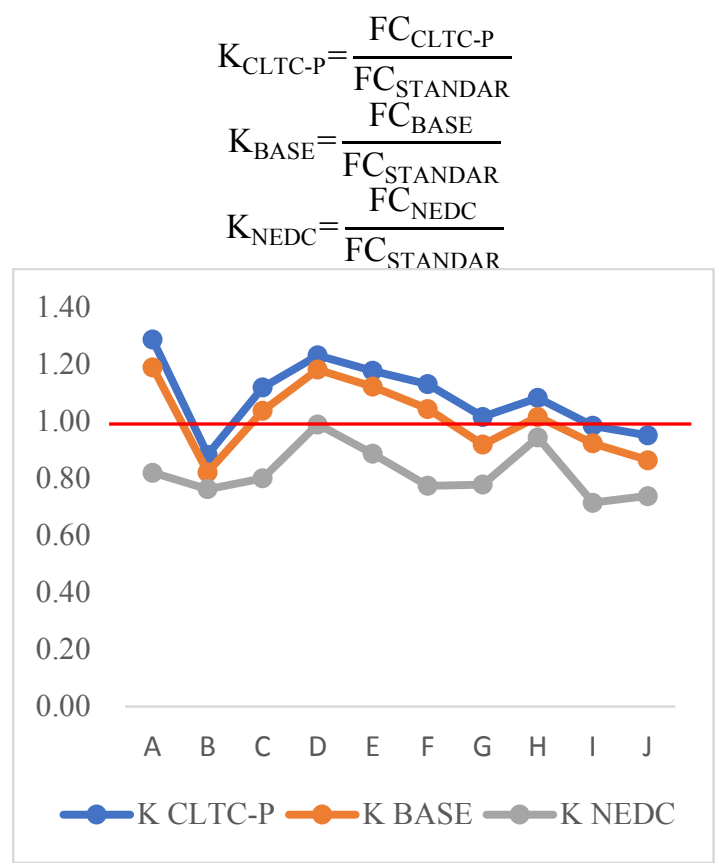

Fig. 6. Fuel consumption factor distribution of cold start test under CLTC-P and NEDC cycles.

As shown in Figure 6, the comprehensive fuel consumption of CLTC-P cycle is significantly higher than that of the base fuel consumption under cold start conditions due to the addition of the fuel consumption of the external cycle air conditioner. After the addition of the fuel consumption results of the external cycle air conditioner, the comprehensive fuel consumption of CLTC-P cycle of model G exceeds the fuel consumption limit, and the test results of model $\mathrm{B}$, model $\mathrm{I}$ and model $\mathrm{J}$ reach below 1.0. The average level of the fuel consumption factor of the car under the CLTC-P cycle is at 1.09 Under CLTC-P cycle, the average level of fuel consumption factor of multipurpose passenger vehicles is 1.08 , the average level of CLTC-P cycle consumption factor of vehicles with displacement above $2.0 \mathrm{~L}$ and $2.0 \mathrm{~L}$ is 1.08 , the average level of CLTC-P cycle factor of vehicles with displacement below $2.0 \mathrm{~L}$ is 1.10 , and the results of CLTC-P cycle fuel consumption are relatively stable, distributed near 1.1 times of the fuel consumption limit.

Table 3. Comparison of comprehensive fuel consumption of cltc-p cycle and NEDC cycle.

\begin{tabular}{|c|c|c|c|}
\hline NO. & $\begin{array}{c}\text { FC CLTC-P } \\
\text { L/100km }\end{array}$ & $\begin{array}{c}\text { FC }_{\text {NEDC }} \\
\text { L/100km }\end{array}$ & Growth rate \\
\hline A & 9.26 & 5.90 & $57.00 \%$ \\
\hline B & 7.41 & 6.40 & $15.81 \%$ \\
\hline C & 8.95 & 6.40 & $39.80 \%$ \\
\hline D & 11.33 & 9.10 & $24.50 \%$ \\
\hline E & 10.36 & 7.80 & $32.81 \%$ \\
\hline F & 9.50 & 6.50 & $46.08 \%$ \\
\hline G & 7.31 & 5.60 & $30.59 \%$ \\
\hline H & 9.53 & 8.30 & $14.77 \%$ \\
\hline I & 8.27 & 6.00 & $37.82 \%$ \\
\hline J & 7.98 & 6.20 & $28.77 \%$ \\
\hline
\end{tabular}

As shown in Table 3, the comprehensive fuel consumption of cltc-p cycle test is higher than that of NEDC cycle, with the highest increase of $57 \%$ for test vehicle a. the comprehensive fuel consumption of CLTC-P cycle test for all test vehicles increases by $32.79 \%$ 
on average. The comprehensive fuel consumption of CLTC-P cycle test for passenger cars increases by $37.80 \%$, the comprehensive fuel consumption of CLTC-P cycle test for multipurpose passenger vehicles increases by $25.29 \%$, and the fuel consumption of vehicles with displacement below 2.0L increases by $35.20 \%$, the result of CLTC-P cycle fuel consumption of vehicles with displacement of $2.0 \mathrm{~L}$ and above increased by $30.39 \%$, and the result of CLTC-P cycle comprehensive fuel consumption of small displacement vehicles increased more.

\section{Conclusions}

(1) In terms of the performance of cold start fuel consumption, the base fuel consumption of CLTC-P cycle is higher than that of NEDC cycle, and the results of some models exceed the fuel consumption limit, with an average increase of $23.55 \%$. The comprehensive fuel consumption of CLTC-P added with the fuel consumption of air conditioning test outside the cycle is $2.17 \mathrm{~L} / 100 \mathrm{~km}$ higher than that of NEDC cycle, with a maximum increase of $57.00 \%$. The comprehensive fuel consumption of air conditioning outside the cycle is in CLTC-P The consumption results account for $4.06 \%-9.55 \%$ [15]. the average proportion of multi-purpose passenger vehicles accounts for $6.21 \%$, and the average proportion of cars accounts for $7.71 \%$. The fuel consumption of out of cycle air conditioning has a great impact on the comprehensive fuel consumption results of sedans in CLTC-P.

(2) Compared with NEDC cycle, cltc-p cycle is more in line with the actual situation of China's long road congestion and long-term low-speed driving, with less idling range and more emphasis on the performance of low-speed stage, and more close to the actual vehicle use in terms of fuel consumption results.

(3) China has a vast territory, four distinct seasons, and a high dependence on air conditioning[16]. Through the analysis of the results, the fuel consumption of out of cycle air conditioning accounts for a relatively high proportion of the fuel consumption results in China. In the future development of fuel consumption laws and regulations, the operation of air conditioning should be taken into consideration in terms of comprehensive fuel consumption, so as to truly feedback the actual fuel consumption of actual vehicles.

\section{Reference}

1. Yuan, X., Liu, X., \& Zuo, J. (2015). The development of new energy vehicles for a sustainable future: A review. Renewable \& Sustainable Energy Reviews, 42(42), 298305.

2. Wang, J., Jin, L., Gao, J., Shi, J., Zhao, Y., Liu, S., ... \& Wu, C. (2013). Investigation of speciated VOC in gasoline vehicular exhaust under ECE and EUDC test cycles. Science of The Total Environment, 110-116.

3. Huo, H., Yao, Z., He, K., \& Yu, X. (2011). Fuel consumption rates of passenger cars in China: Labels versus real-world. Energy Policy, 39(11), 7130-7135.

4. Zhang, S., Wu, Y., Liu, H., Huang, R., Un, P., Zhou, Y., ... \& Hao, J. (2014). Real-world fuel consumption and $\mathrm{CO} 2$ (carbon dioxide) emissions by driving conditions for lightduty passenger vehicles in China. Energy,, 247-257.

5. Jaworski, A., Kuszewski, H., Ustrzycki, A., Balawender, K., Lejda, K., \& Woś, P. (2018). Analysis of the repeatability of the exhaust pollutants emission research results for cold and hot starts under controlled driving cycle conditions. Environmental Science and Pollution Research, 25(18), 17862-17877. 
6. Huo, H., He, K., Wang, M., \& Yao, Z. (2012). Vehicle technologies, fuel-economy policies, and fuel-consumption rates of Chinese vehicles. Energy Policy,, 30-36.

7. Bielaczyc, P., Woodburn, J., and Szczotka, A., "A Comparison of Carbon Dioxide Exhaust Emissions and Fuel Consumption for Vehicles Tested over the NEDC, FTP-75 and WLTC Chassis Dynamometer Test Cycles," SAE Technical Paper 2015-01-1065, 2015, doi:10.4271/2015-01-065.

8. Robert Joumard, Michel Andre, Robert Vidon, Patrick Tassel, C Pruvost Influence of driving cycles on unit emissions from passenger cars Atmospheric Environment Paper 4621-4628 20002734.

9. Yusuf, A. A., \& Inambao, F. L. (2019). Effect of cold start emissions from gasolinefueled engines of light-duty vehicles at low and high ambient temperatures: Recent trends. Case Studies in Thermal Engineering,.

10. Nakama, K., Murase, E., Kusaka, J., \& Daisho, Y. (2005). Effects of high temperature fuel on fuel consumption and emissions under the cold start condition of direct injection gasoline engines. Transactions of the Japan Society of Mechanical Engineers. B, 71(707), 1947-1954.

11. Weilenmann, M., Vasic, A., Stettler, P., \& Novak, P. (2005). Influence of mobile airconditioning on vehicle emissions and fuel consumption: A model approach for modern gasoline cars used in Europe. Environmental Science \& Technology, 39(24), 9601-9610.

12. Berkeley; Arnold D. (Potomac, MD), Jefferson; Donald E. (Silver Spring, MD). (1998). Method and apparatus for conserving peak load fuel consumption and for measuring and recording fuel consumption.

13. Rahman, S. M., Masjuki, H. H., Kalam, M. A., Abedin, M. J., Sanjid, A., \& Sajjad, H. (2013). Impact of idling on fuel consumption and exhaust emissions and available idlereduction technologies for diesel vehicles - A review. Energy Conversion and Management, 171-182.

14. Oomura, M. , Takeo, Y. , \& Takahashi, E. . (2001). Vehicle air conditioner with reduced fuel consumption of vehicle engine.

15. Zhang, S., Wu, Y., Liu, H., Huang, R., Yang, L., Li, Z., ... \& Hao, J. (2014). Real-world fuel consumption and $\mathrm{CO} 2$ emissions of urban public buses in Beijing. Applied Energy,, 1645-1655.

16. Zhang, S., Wu, Y., Liu, H., Huang, R., Un, P. , \& Zhou, Y., et al. (2014). Real-world fuel consumption and co_2 (carbon dioxide) emissions by driving conditions for lightduty passenger vehicles in china. Energy, 69(may), 247-257. 